\title{
Editorial
}

\section{Baseball, trains and planes}

Journal of Revenue and Pricing Management (2012) 11, 485-486. doi:10.1057/rpm.2012.33

The central premise of Moneyball (Lewis, 2003), is that the collected wisdom of baseball insiders (including players, managers, coaches, scouts and the front office) over the past century is subjective and often flawed. Statistics such as stolen bases, runs batted in and batting average, typically used to gauge players, are relics of a nineteenth century view of the game and the statistics that were available at the time. The book argues that the Oakland A's' front office took advantage of more analytical gauges of player performance to field a team that could compete successfully against richer competitors in Major League Baseball. Rigorous statistical analysis had demonstrated that on-base percentage and slugging percentage are better indicators of offensive success, and the A's became convinced that these qualities were cheaper to obtain on the open market than more historically valued qualities such as speed and contact. These observations often flew in the face of conventional baseball wisdom and the beliefs of many baseball scouts and executives. The book, shows relevant statistics and on a scientific approach to baseball allowed him to achieve winning seasons despite being burdened by severe budget constraints, hence the value of good and robust data analysis. All of this has been made possible with the advance of technology, as Yip identifies in the Futures article in this issue we are living in an age where technology allows the speed of information to be collected and analysed quickly and accurately. The age of Management Science is upon us - with Revenue Management at the forefront in capacity constrained inventory. Good baseball decisions are like good Revenue Management decisions.
These good decisions are what Sato and Sawaki present as an interesting concept through the evolution of Revenue Management models in rail transport. The authors present a revenue management model of dynamic pricing for a competitive route supposing that the passengers are allowed to choose among other transport modes and that each transport mode offers the multiple substitutable schedules. In addition, the cancellation, no-show and overbooking are incorporated into the model, using the multinomial LOGIT (MNL) model to describe the customer's discrete choice and derive an optimal pricing policy so as to maximize the expected total revenue for substitutable schedules for High Speed Rail. Whereas Dutta and Ghosh use a mathematical model for a Revenue Management System that consists of an optimizer, a simulator and a forecaster, and implement these systems on the National Railway of an Emerging Asian Economy. The authors formulate a multi-period network revenue optimization model based on deterministic linear programming, which emphasizes capacity allocations adjusted to the leg-based passenger demand. Central to this practitioner paper is the adoption of an airline Expected Marginal Seat Revenue (EMSR) approach in a rail transport context.

Topaloglu duality approach for network alliances develop a revenue management model for airline alliances to allow the members of the alliance to decide how to share the revenues from itineraries spanning flight legs operated by multiple airlines and how to coordinate their capacity allocation decisions. The importance 
of the paper lies in the issue that building alliances represents one of the most vital tactics for increasing market share and ensuring profitability for airlines. Through codeshare agreements, members of an alliance gain access to the inventory of seats available on the flight legs operated by the other airlines in the alliance, allowing them to serve origin destination markets that would be impossible to serve by using only their own networks. The significance of the model allows each airline to make its capacity control decisions autonomously, whereas considering its impact on the whole alliance. On the technical side, if an airline does not market a particular itinerary, then its revenue share of the itinerary should simply be equal to the total opportunity cost of the seats consumed by the itinerary on the flight legs operated by this airline. However, the model provides a justification for this intuition for large airline networks.

Weatherford and Khokhlov examine how the general Dynamic Programming (DP) theory is applied in practice to the airline problem. The authors use simulation analysis to show the difference in the expected revenue performance of such deterministic DP-based bid prices, compared with linear programming based bid price control and EMSR leg control. The benefits of the approach encourages both airline managers and Revenue Management system vendors to explore the use of LP/DP together as a way to increase revenues on small sub-networks (5-10 legs) of an airline's overall network. Ferguson and colleagues research paper addresses how choice-based revenue management algorithms directly integrate a discrete choice model of customer behaviour into the optimization function. Using a Matching Shares Property of MNL models, the authors show that estimated choice model parameters will match probabilities in the estimation data set for MNL models that include alternative specific constants (ASCs). The research article has focused on illustrating how correct specification on the utility function, and in particular, inclusion of ASCs is critical in discrete choice modelling applications. So, as Revenue Management adopts more advanced discrete choice models it will be important to examine how closely models that include ASCs approximate sample shares and whether this affects the overall forecasting performance of the choice-based RM model.

\section{REFERENCE}

Lewis, M. (2003) Moneyball: The Art of Winning an Unfair Game. New York: Norton Publications.

Ian Yeoman

Editor

Journal of Revenue \& Pricing Management, Victoria University of Wellington,

New Zealand 